\title{
¿Subseasonal Forecast Skill of Snow Water Equivalent and Its Link with Temperature in Selected SubX Models
}

\author{
G. T. DIRO AND H. LIN \\ Meteorological Research Division, Environment and Climate Change Canada, Dorval, Quebec, Canada
}

(Manuscript received 9 April 2019, in final form 26 November 2019)

\begin{abstract}
Accurate and skillful subseasonal forecasts have tremendous potential for sectors that are sensitive to hazardous weather and climate events. Analysis of prediction skill for snow water equivalent (SWE) and near-surface air temperature (T2m) is carried out for three (GEPS, GEFS, and FIM) global models from the subseasonal experiment (SubX) project for the 2000-14 period. The prediction skill of SWE is higher than the skill of T2m at week-3 and week-4 lead times in all models. The GEPS forecast tends to yield higher (lower) prediction skill of SWE (T2m) compared to the other two systems in terms of correlation skill score. The snow-temperature relationship in reanalysis is characterized by a strong negative correlation over most of the midlatitude regions and a weak positive correlation over high-latitude Arctic regions. All forecast systems reproduced well these observed features; however, the snow-temperature relationship is slightly weaker in the GEPS model. Despite the apparent lack of skill in temperature forecasts at week 4, all three models are able to predict the sign of temperature anomalies associated with extreme SWE conditions albeit with reduced intensity. The strength of the predicted temperature anomaly associated with extreme snow conditions is slightly weaker in the GEPS forecast compared to reanalysis and the other two models, despite having better skill in predicting SWE. These apparent disparities suggest that weak snow-temperature coupling strength in the model is one of the contributing factors for the lower temperature skill.
\end{abstract}

\section{Introduction}

Anomalous weather- and climate-related natural disasters are one of the most common misfortunes and are associated with severe socioeconomic consequences (e.g., Hoeppe 2016). Accurate predictions of such weather and climate anomalies with sufficient lead time have enormous benefits for decision-makers. Until recently, short-range numerical weather prediction models produce skillful forecasts of up to a week or 10 days as the weather forecasts rely heavily on the atmospheric initial condition. Coupled climate models, on the other hand usually produce skillful seasonal mean forecasts with lead times of a season or several months in advance as the main source of the skill for this time scale is the lower boundary condition such as sea surface temperature (SST). This approach

Denotes content that is immediately available upon publication as open access.

Corresponding author: G. T. Diro, gulilat.diro@canada.ca essentially left a subseasonal prediction gap (i.e., time scale between weather forecasts and seasonal prediction) (Hudson et al. 2011; Vitart et al. 2012, 2017). Furthermore, producing a skillful forecast on this subseasonal time scale presents a challenge as the role of atmospheric initial conditions is not as strong as in the short range and, in the meantime, the impact of slowly varying boundary conditions has not reached a level where it becomes a dominant player (Vitart et al. 2012).

Despite the above challenge, various sectors increasingly demand and use subseasonal forecasts in their planning for decision support systems (White et al. 2017). For instance, subseasonal predictions have been tested for the purpose of hydrological forecasting and water resource management (Shah et al. 2017; Bogner et al. 2018), flood prediction (White et al. 2015), energy and reservoir operation (Alemu et al. 2011), early warning of vector-borne diseases (Lowe et al. 2016; Tompkins et al. 2019), and for optimizing agricultural activities (Calanca et al. 2011). Owing to this importance, coordinated projects such as the Subseasonal to 
Seasonal Prediction project (S2S; Robertson et al. 2015; Vitart et al. 2017) and the Subseasonal Prediction Experiment (SubX; Pegion et al. 2019) have been initiated with the aim of disseminating as well as improving further the skill of subseasonal forecasts. Consequently, numerous studies have been carried out to investigate the skill of subseasonal forecasts of selected near surface atmospheric variables such as temperature, precipitation, and upper-level air fields from these projects (e.g., Lin and Brunet 2011; Lynch et al. 2014; Liu et al. 2014; Vitart 2014; Li and Robertson 2015; White et al. 2015; Wanders and Wood 2016; Vigaud et al. 2017; Liang et al. 2018; Lin 2018; Xiang et al. 2019). However, less attention has been given to the assessment of land surface variables such as snow and soil moisture conditions, despite their impact in modulating the variability as well as extremes of regional temperature and precipitation events over selected land-atmosphere coupling hot spots (e.g., Koster et al. 2004; Xu and Dirmeyer 2011; Dutra et al. 2011; Diro and Sushama 2018; Diro et al. 2018). As land is one of the important boundary conditions in the forecasting models, several studies have demonstrated the key role of prescribing realistic initial soil moisture and snow conditions on the skill of temperature and to some extent precipitation forecasts both at seasonal (P. Lin et al. 2016; Koster and Suarez 2003; Paolino et al. 2012; Prodhomme et al. 2016) and subseasonal (Koster et al. 2010; Jeong et al. 2013; Hirsch et al. 2014; Orsolini et al. 2013; Thomas et al. 2016) time scales. Nevertheless, the evolution of these surface variables within the subseasonal forecast horizon is yet to be investigated in detail, particularly in the context of S2S or SubX projects.

The aim of this study is to conduct a multimodel comparison of the snow water equivalent prediction skill using selected models from the SubX archive and to investigate its link with surface temperature at lead times of 1-4 weeks. This is achieved by analyzing the temporal correlation of snow water equivalent (SWE) and near-surface air temperature (T2m) as well as by identifying the main mode of subseasonal variability of Northern Hemisphere snow water equivalent using an empirical orthogonal function (EOF) analysis and then attempting to relate the temperature forecast skill to extreme high and low SWE events of the leading mode of SWE variability in reanalysis and forecasts.

The rest of the paper is organized as follows. In section 2, we describe the models employed, the validation dataset, and the methodology used. Section 3 presents the results of the forecast skill and the snowtemperature relationship, as well as the skill of temperature forecasts during anomalous snow conditions.
Finally a summary and conclusions will be given in section 4.

\section{Data and methods}

The subseasonal forecasts considered for this study are taken from three forecast systems that are part of the SubX (Pegion et al. 2019) project. These three models are selected because they provide the daily snow water equivalent required for this study and also for their similarity in the frequency of their start date, which makes the comparison easier. These models are Environment and Climate Change Canada's Global Ensemble Prediction System (ECCC-GEPS; H. Lin et al. 2016), National Centers for Environmental Prediction/Environmental Modeling Center's Global Ensemble Forecast System (NCEP/EMC-GEFS; Zhou et al. 2017; Zhu et al. 2018), and NOAA Earth System Research Laboratory's Flow-following Icosahedral Model (ESRL-FIM; Sun et al. 2018a,b). In SubX, there is no fixed standard on the size of ensembles or initialization procedure for atmosphere, land, and ocean. There are, however, minimum requirements, such as the minimum number of days in the integration period of 32 days. All three models are initialized every week, every Wednesday for the FIM and GEFS models and every Thursday for GEPS. A description of the models, initialization dates, and number of ensemble members are presented in Table 1. As shown in Table 1, the land surface scheme used in GEFS and FIM is Noah (Koren et al. 1999; Ek et al. 2003), whereas GEPS uses the Interactions between Soil, Biosphere, and Atmosphere (ISBA; Noilhan and Planton 1989; Bélair et al. 2003) scheme. Both the ISBA and Noah land surface models have a single-layer snow scheme. It is also important to note that land surface (including that of snow) initial conditions for GEPS are obtained from separate offline land surface simulations driven with ERA-Interim (Dee et al. 2011) reanalysis fields. In GEFS and FIM, on the other hand, surface initial conditions are obtained from a reanalysis dataset such as CFSR and GDAS. In the reanalysis, snow is analyzed by assimilating the SNODEP model (Kopp and Kiess 1996) and snow cover data from Interactive Multisensor Snow and Ice Mapping System (IMS; Helfrich et al. 2007). Only forecasts initialized during the cold season (between the last week of November and the first week of March) are considered. All the three models provide daily snow water equivalent (SWE) and daily mean temperature at a $1^{\circ} \times 1^{\circ}$ spatial resolution. From daily data, 4 weekly means are computed for days 5-11 (week 1), days 12-18 (week 2), days 19-25 (week 3), and days 26-32 (week 4). For each grid point and each week, the climatological 
TABLE 1. Name and description of the models employed in this study.

\begin{tabular}{|c|c|c|c|c|}
\hline Model & Institute & $\begin{array}{c}\text { Land } \\
\text { scheme }\end{array}$ & Initialization & $\begin{array}{c}\text { Ensemble } \\
\text { size }\end{array}$ \\
\hline $\begin{array}{l}\text { Global Ensemble Prediction System } \\
\text { (GEPS) }\end{array}$ & Environment and Climate Change Canada & ISBA & Every Thursday & 4 \\
\hline $\begin{array}{l}\text { Global Ensemble Forecasting System } \\
\text { (GEFS) }\end{array}$ & NCEP Environmental Prediction Center & Noah & Every Wednesday & 11 \\
\hline $\begin{array}{l}\text { Flow-following Icosahedral Model } \\
\text { (FIM) }\end{array}$ & NOAA/Earth System Research Laboratory & Noah & Every Wednesday & 4 \\
\hline
\end{tabular}

seasonal cycle is removed by subtracting the climatological value for that week. The seasonal average value of each year is also subtracted from each week to further remove the interannual variability and, hence, retain only the intraseasonal variability.

One of the biggest challenges in evaluating forecast skill is the choice of a verification dataset, particularly for derived fields such as snow water equivalent. For this study, the fifth major global reanalysis produced by ECMWF (ERA5; Hersbach and Dee 2016) is employed as a validation dataset both for $\mathrm{T} 2 \mathrm{~m}$ and SWE variables. Although ERA5 is produced at a $31-\mathrm{km}$ horizontal resolution, the dataset is downloaded at $0.5^{\circ}$ horizontal resolution for the 2000-14 period at an hourly interval. The hourly datasets are then converted to weekly mean values to match each forecast system hindcast. Both the hindcasts and ERA5 are interpolated to a common grid of $1^{\circ} \times 1^{\circ}$ resolution for each climate variable. Analysis is then carried out for the common 14 years starting from 2000 to 2014.

To analyze the skill of SWE prediction in more detail, the leading EOF and the associated principal component (PC) have been examined. Consequently, an areaweighted EOF analysis is performed on the weekly mean anomalies containing 196 weekly hindcast fields (14 years and 14 weeks) and for all land grid points of the Northern Hemisphere.

\section{Results and discussion}

\section{a. Forecast climatology and subseasonal variability of SWE and T2m}

The spatial pattern of climatological SWE bias in the three forecast systems compared to ERA5 during the cold season at different lead times is shown in Fig. 1. The climatology of SWE (not shown) during winter is higher over the complex topography of western North America and northern Eurasia, reaching an excess of $200 \mathrm{~mm}$ over the Rocky Mountains and Tibetan Plateau. Overall the bias in the three models is identical with strong underestimation in SWE forecasts over the complex topographies of the Rocky Mountains and Tibet at all lead times. However, it has to be noted that the negative bias over complex topography such as over the Tibetan Plateau is also related to the pronounced excess snow in the ERA5 reanalysis as shown in Orsolini et al. (2019). The GEFS and FIM models additionally show a negative bias over northeastern Canada. It is interesting to note that the bias of SWE decreases as the forecast lead time increases for the FIM and GEFS models. This is possibly due to strong underestimation in the initial conditions, which causes larger negative biases at shorter lead times over northern Eurasia and eastern North America. It has to be noted that climatological bias cannot be taken as the key indicator of forecast skill as a model with a large climatological bias can still produce skillful forecasts.

To examine the subseasonal forecast skill, the correlation coefficients between the reanalysis and hindcast anomalies are also computed for the ensemble mean. Figure 2 shows the spatial pattern of temporal correlation skill (after removing both the seasonal cycle and interannual variability) for the weekly mean SWE hindcast for each forecast system at lead times of 14 weeks. Only significant correlations at the 0.05 level are displayed. In all forecast systems, the forecast skill for SWE is higher at week 1 and decays as the lead time progresses. For GEPS, the highest skill covers most of the high-latitude regions whereas for the GEFS and FIM models the highest skill is concentrated over eastern North America and over Europe. Like the bias, the forecast skill is similar between GEFS and FIM, possibly due to the fact that these models share similar physics packages including the land surface model (Noah; Koren et al. 1999; Ek et al. 2003). Comparing among the forecast systems, the forecast skill of GEPS is higher than both GEFS and FIM for all lead times.

The above analysis provides us with the general characteristics of snow water equivalent when a gridpointby-gridpoint comparison is carried out. We next focus on the leading mode of subseasonal variability analysis in SWE forecasts. EOF analysis is applied to the predicted SWE of the ensemble mean forecasts and for the reanalysis field. Figures 3 and 4 show the spatial loading of the first EOF for ERA5 and for the three forecast 

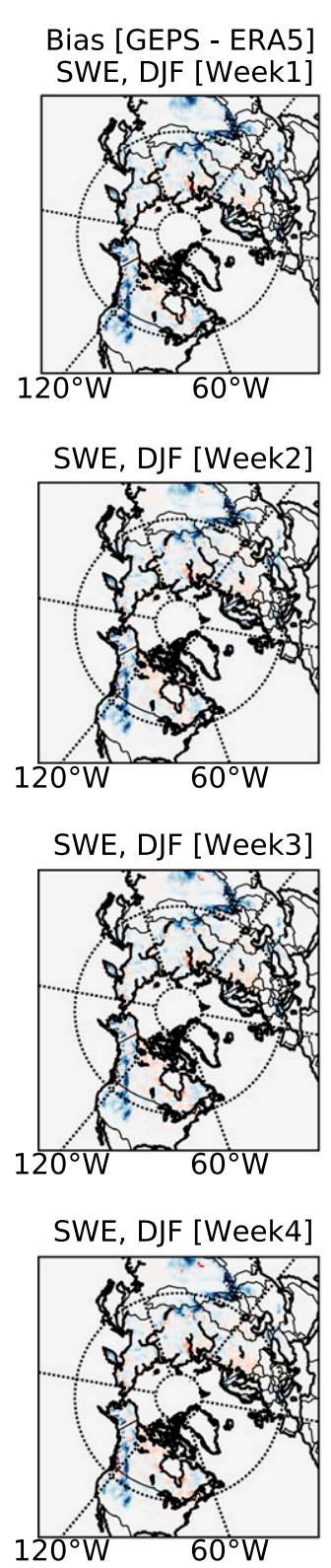

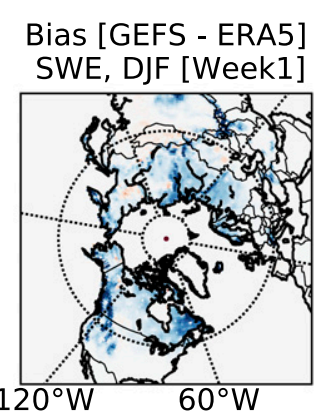

SWE, DJF [Week2]
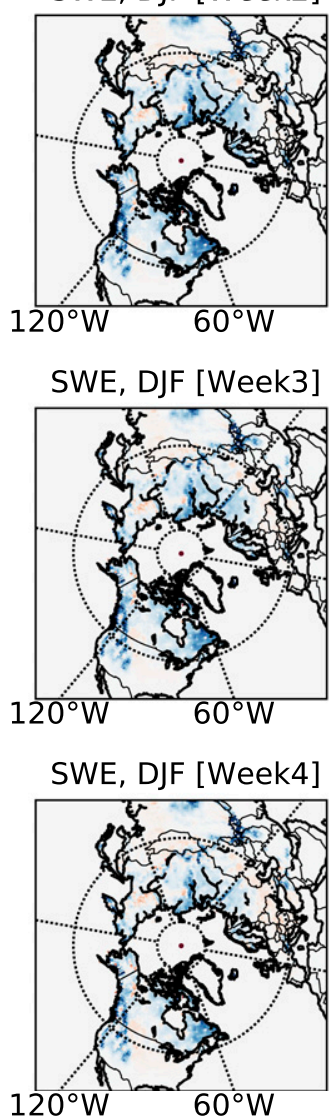

Bias [FIM - ERA5] SWE, DJF [Week1]

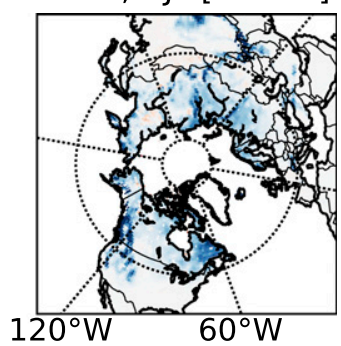

SWE, DJF [Week2]

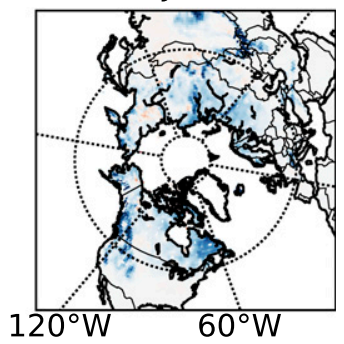

SWE, DJF [Week3]

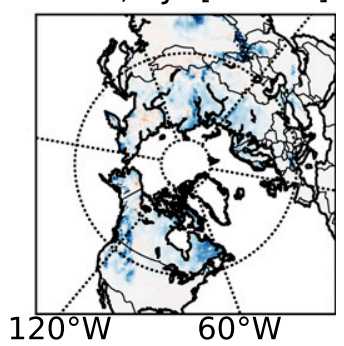

SWE, DJF [Week4]

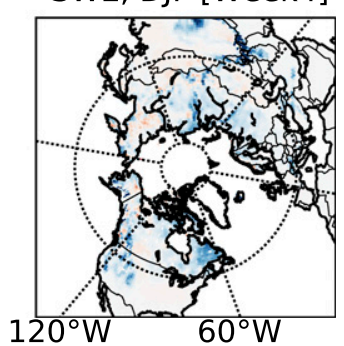

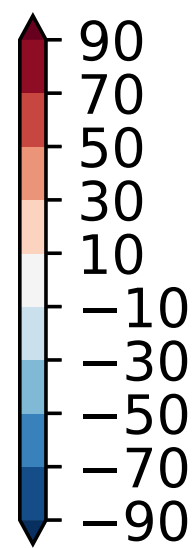

FIG. 1. SWE (mm) bias in the subseasonal forecasts from the (left) GEPS, (center) GEFS, and (right) FIM models at lead times of (first row) week 1, (second row) week 2, (third row) week 3, and (fourth row) week 4.

systems for lead times of weeks 1 and 4 . The first SWE EOF explains $12 \%$ of the subseasonal variability in ERA5 and $9 \%-30 \%$ in the three forecast systems. In ERA5, the first EOF is characterized by a dipole pattern over Eurasia with a positive anomaly over northern Asia and a negative anomaly over central Europe. This mode also shows a moderate negative anomaly over most of Canada. GEPS predicted the spatial pattern of this mode successfully at both lead times, though the fraction of variance explained is underestimated. The GEFS and FIM forecast systems, on the other hand, predicted the positive anomaly over northern Asia but missed the pattern elsewhere. Notably the forecasts show an opposite pattern (positive anomaly) over northern North America and underestimate the negative anomaly over central Europe. The fraction of variance explained by the first mode is substantially higher in the FIM forecast system ranging from $30 \%$ for lead times of week 1 (Fig. 3) to $21 \%$ at week 4 (Fig. 4).

Figure 5 shows the spatial pattern of the subseasonal correlation skill for the temperature forecast over land points and for lead times of 1-4 weeks from all the three 

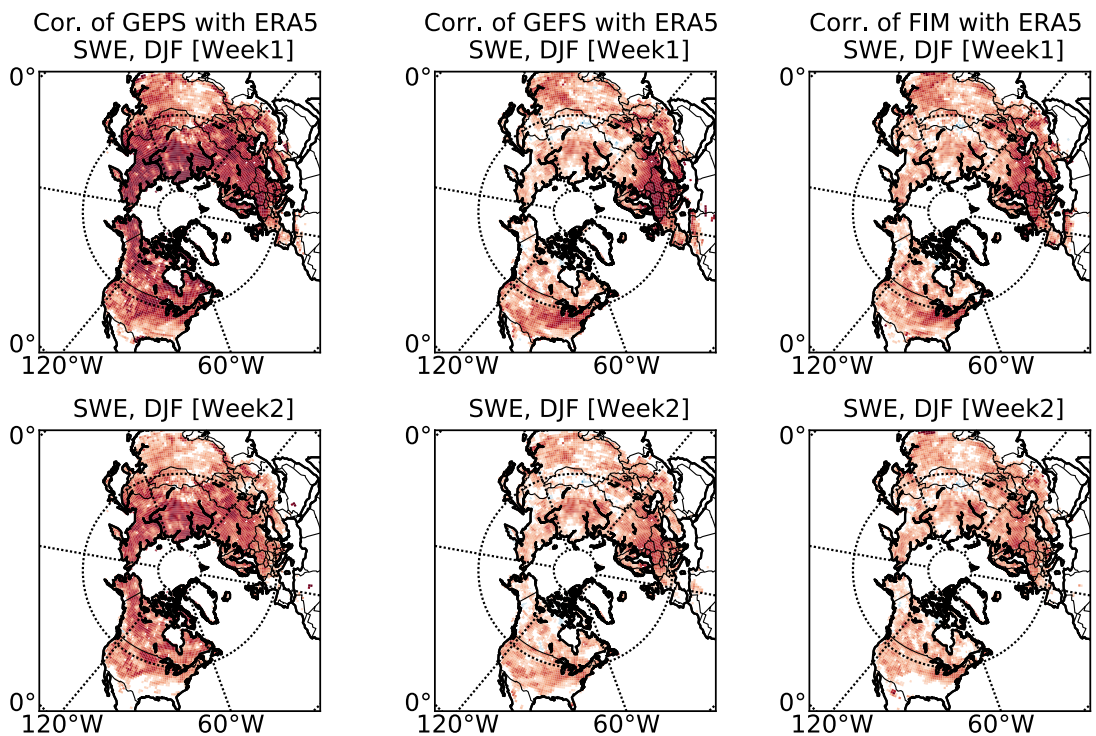

SWE, DJF [Week3]
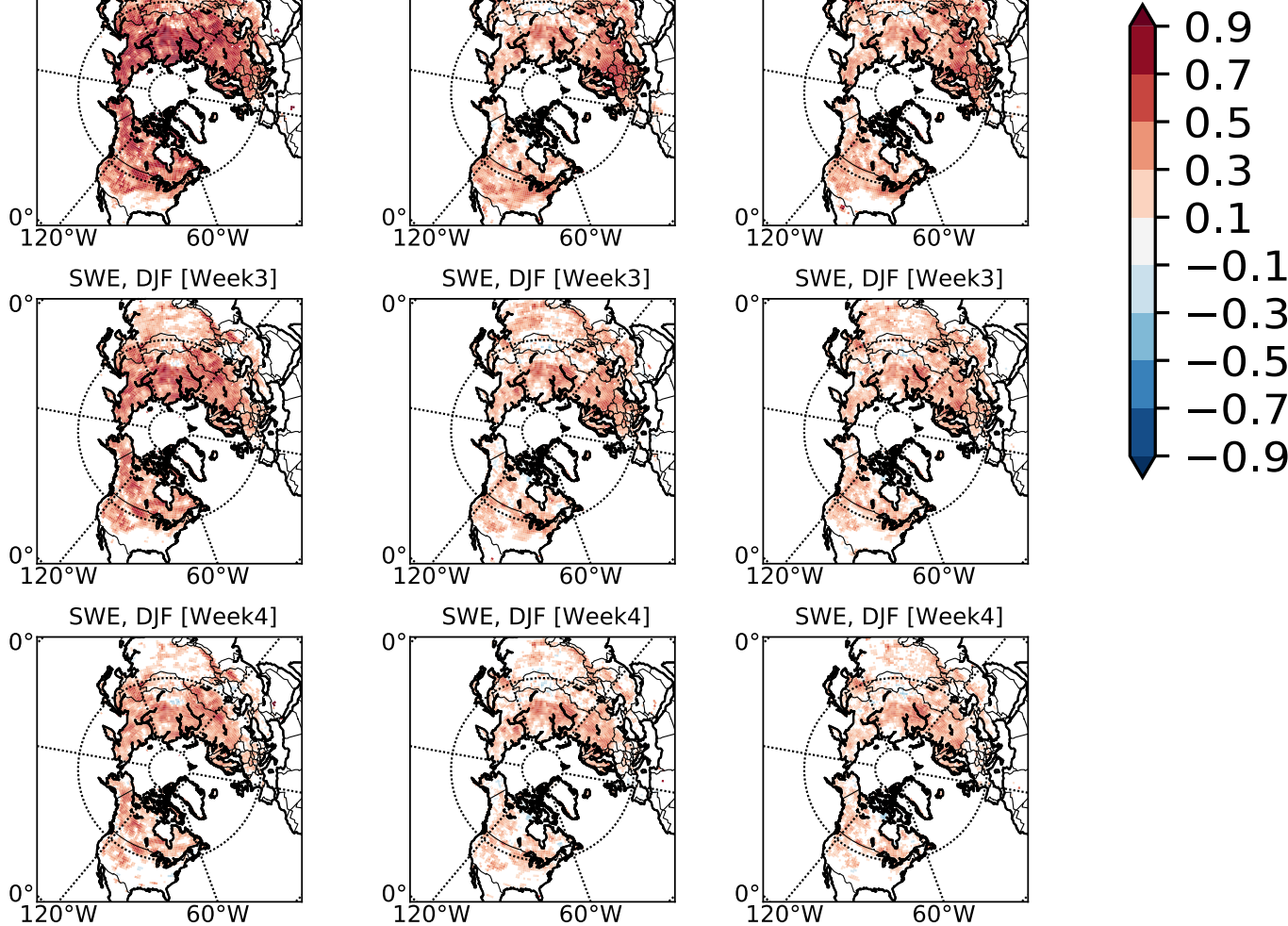

FIG. 2. SWE anomaly correlation between ERA5 and subseasonal forecasts from (left) GEPS, (center) GEFS, and (right) FIM at lead times of (first row) week 1, (second row) week 2, (third row) week 3, and (fourth row) week 4. Only significant correlations at the 0.05 level are displayed.

forecast systems. Areas with anomaly correlation that are not statistically significant are masked with a white color. The correlation for 1-week lead is greater than 0.6 over most of the land points and is above 0.8 over some regions such as the eastern United States, western Canada, and central Asia. The forecast skill is generally higher at high latitudes compared to tropical regions such as eastern South America and southern Africa. The correlation values decrease rapidly from $>0.8$ at week 1 to a correlation value $<0.4$ at week 2 for most of the land areas. As the lead time further increases the correlation values continue to decrease and by week 4 , the regions of significant correlation are mostly confined to few low-latitude regions. In all forecast systems, the correlation skill decreases faster in the extratropics compared to the tropics and this highlights the important role of slowly evolving (e.g., SST) boundary conditions for the low-latitude regions.

\section{b. Local snow water equivalent-temperature relationship}

Establishing a link between snow on the ground and near-surface air temperature is important as snow can modulate the air temperature anomaly at a longer lead time. The simplest way to investigate the relationships between T2m and SWE is to compute the temporal 

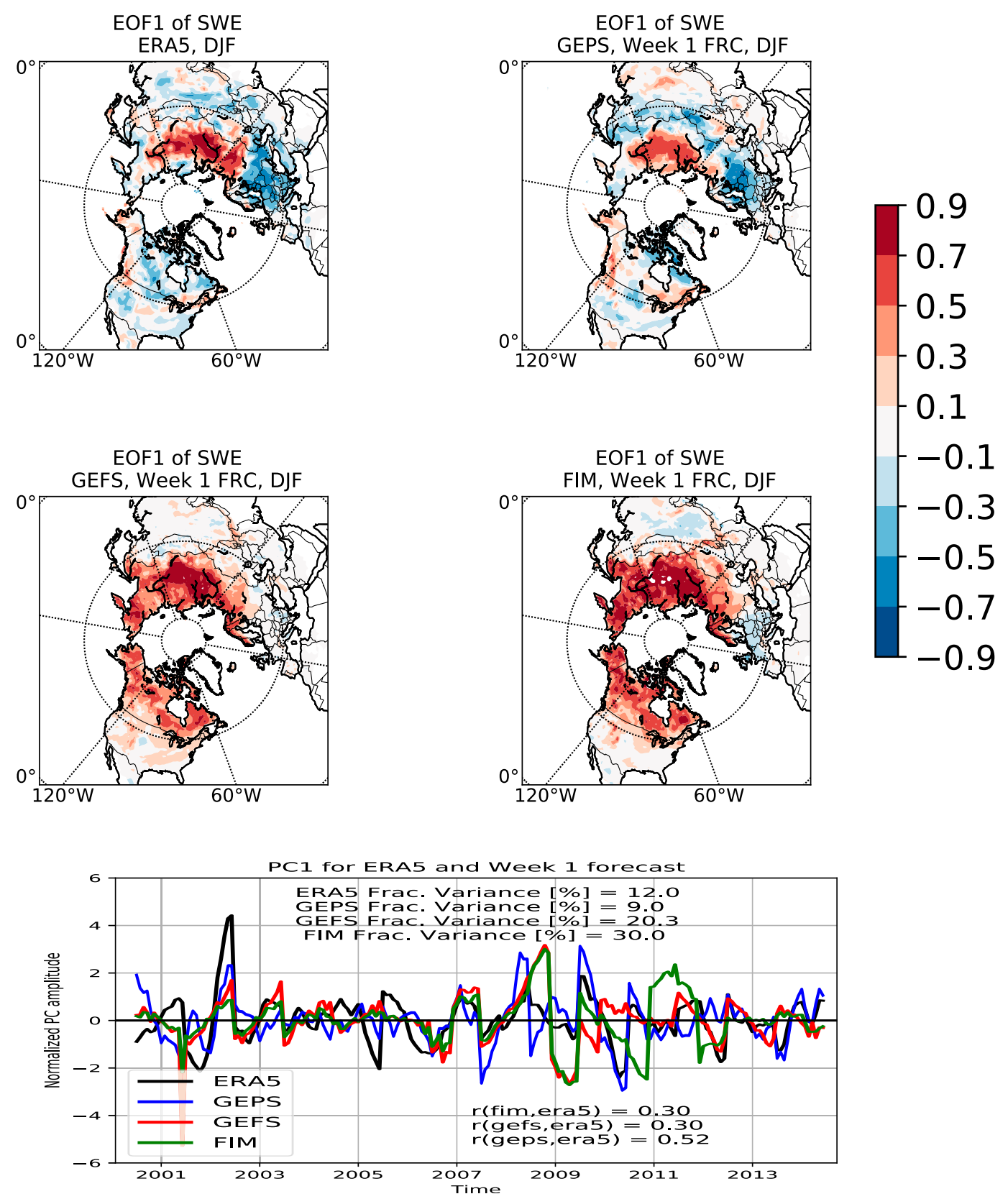

FIG. 3. Spatial pattern of the first EOF for subseasonal variability of SWE from (top left) ERA5 reanalysis and from week-1 forecasts of (top right) GEPS, (middle left) GEFS, and (middle right) FIM. (bottom) The corresponding PC1 time series.

correlation for each grid point and identify the extent and nature of the relationship from the spatial pattern of correlation. The local SWE-T2m correlation in the ERA5 reanalysis shows a pronounced spatial dipole pattern as demonstrated by the spatial pattern of correlation shown in Fig. 6. It is apparent that most of the midlatitude regions exhibit a significant negative correlation whereas for higher-latitude regions such as Arctic Canada and northern Asia, none or a weak positive relationship is noted, indicating latitudinal asymmetry in the SWE-T2m relationship. The negative correlation over the midlatitude regions, to some extent, is due to the influence of SWE conditions on surface temperature (Foster et al. 1983) as snow cover fraction in most models is parameterized as a function of SWE. These regions can be considered as local snow-temperature coupling hot spots [or cold spots as they are termed in Xu and Dirmeyer (2011)]. 

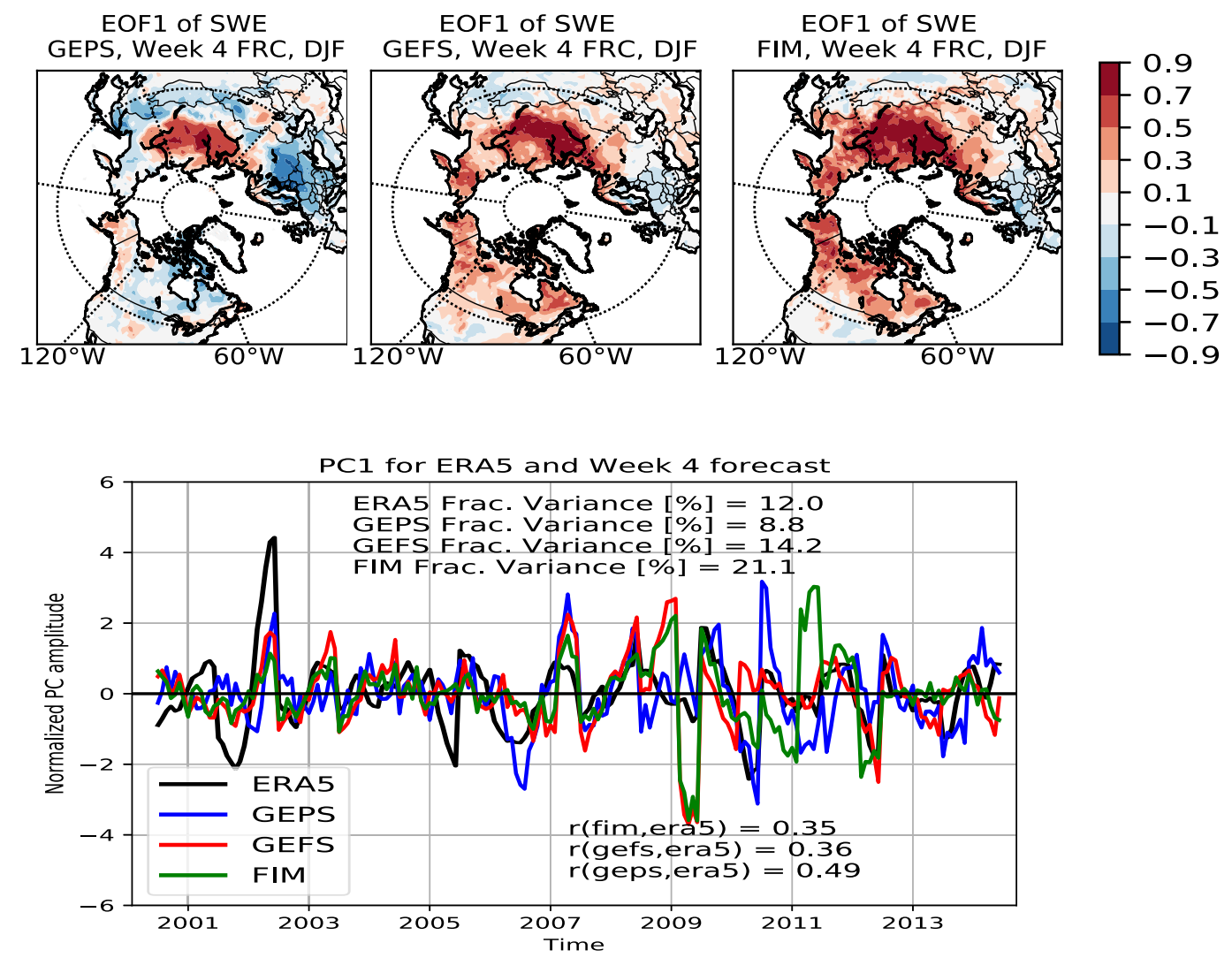

FIG. 4. Spatial pattern of the first EOF for subseasonal variability of SWE for week 4 from the (top left) GEPS, (top center) GEFS, and (top right) FIM forecast systems and (bottom) their corresponding PC1.

However, it has to be noted that such a significant negative correlation between SWE and temperature can also arise as a result of the large-scale atmosphere circulation influencing both SWE and temperature. The apparent positive relationship at higher latitude appears to be dictated by the Clausius-Clapeyron relationship; warmer temperatures lead to higher moisture content, which results in higher snowfall and hence higher snow water equivalent (Davis et al. 1999). All three forecast systems capture the spatial pattern of the SWE-temperature relationship quite well. As in the observations, a significant negative correlation is noted in the midlatitude region and the apparent lack of or weak relationship at higher latitudes. There are, however, notable differences in the magnitude of the correlation between reanalysis and forecasts, particularly in GEFS and FIM. In the GEFS and FIM models, the magnitude of the correlation is higher over the midlatitude regions and extends farther north compared to observations. Another notable feature of this relationship in all forecast systems is that the strength and the pattern of this relationship are not weakening with forecast lead time, even if the forecast skill of both temperature and SWE is declining with time.

\section{c. Forecast skill associated with extreme SWE cases}

We employ composite analysis of near-surface air temperature based on high and low value SWE conditions. The high and low conditions of SWE are selected based on the leading PC of the snow water equivalent mode of subseasonal variability of ERA5 resulting in values $>2.0$ and $<-2.0$, respectively. Each composite contains from four to five cases. High PC values correspond to weeks in January and February 2002 whereas low PC values occurred in December 2001, February 2005, and February 2010. Figure 7 shows the spatial pattern of the temperature anomaly associated with high minus low PC1 of ERA5 SWE from reanalysis as well as forecasts at lead times of week 1 and week 4 . This pattern is characterized by a strong warm anomaly in excess of $9^{\circ} \mathrm{C}$ over Europe and a cold anomaly of $-11^{\circ} \mathrm{C}$ over northern Canada associated with high minus low PC1 of SWE. All three forecast systems predicted this pattern of temperature anomalies well at week 1 . It is interesting to note that although the local snow-temperature 

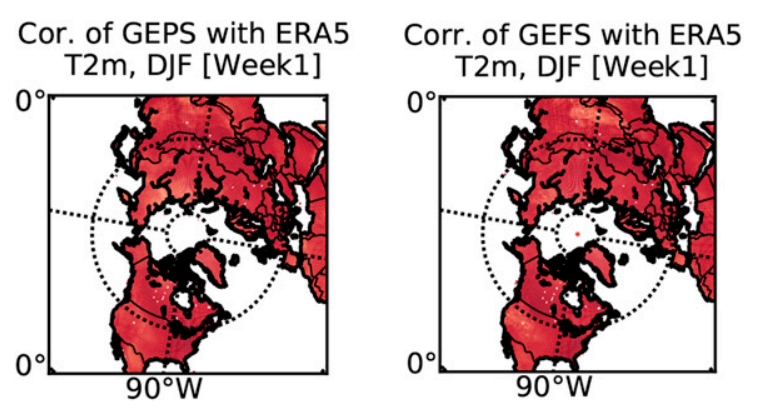
Corr. of FIM with ERA5 T2m, DJF [Week1]
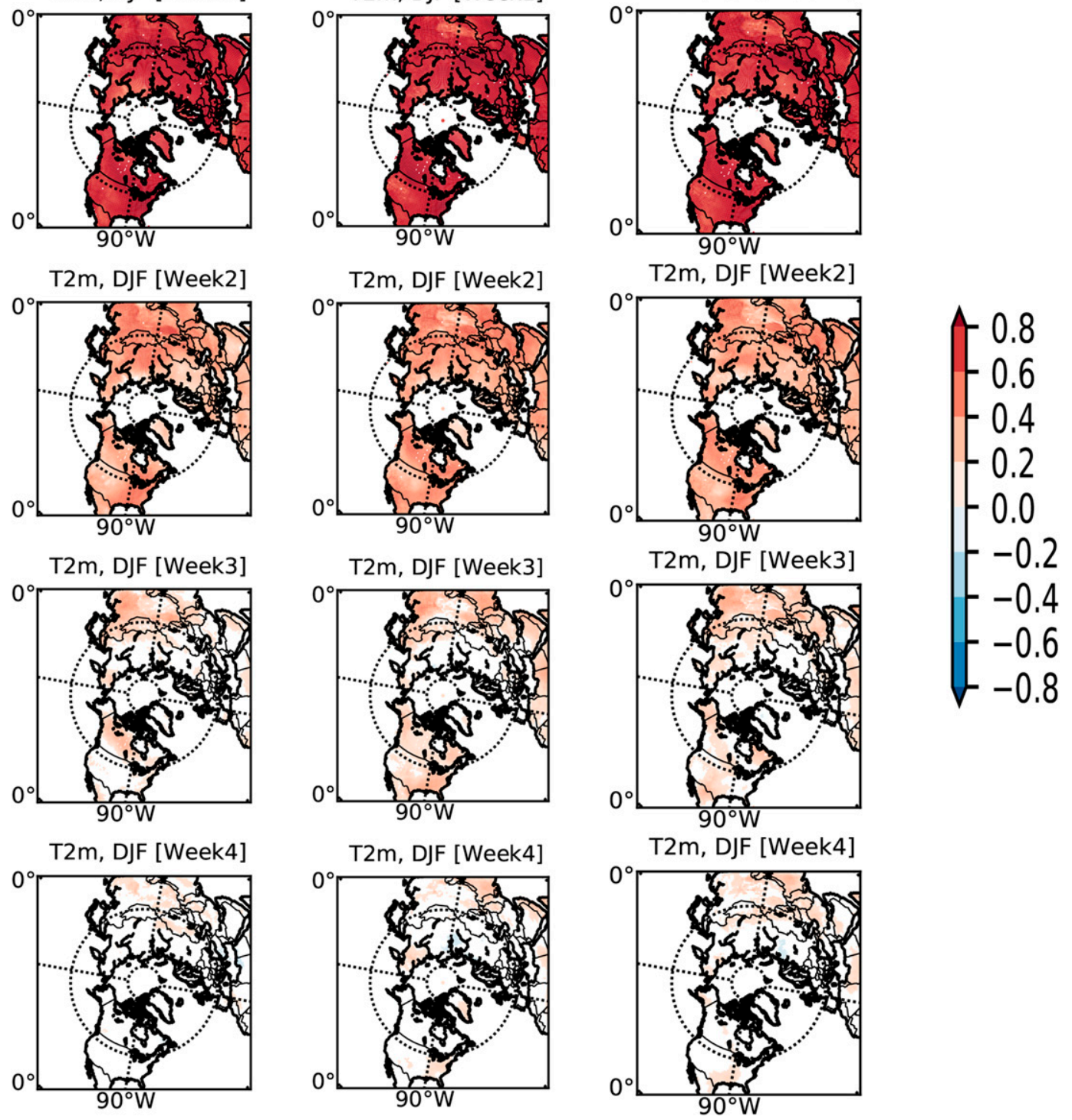

FIG. 5. T2m anomaly correlation between ERA5 reanalysis and subseasonal forecasts from (left) GEPS, (center) GEFS, and (right) FIM at lead times of (first row) week 1, (second row) week 2, (third row) week 3, and (fourth row) week 4 . Only significant correlations at the 0.05 level are displayed.

coupling is weaker over high-latitude Arctic regions, the temperature response of these regions to the leading mode of Northern Hemisphere (NH) SWE variability is significantly higher, suggesting that the NH SWE variability can have a strong remote impact beyond the local snow-temperature coupling hot spots such as over the Arctic or northern Africa. As expected the magnitude of the temperature anomaly decays with lead time in all models, but the models are still able to correctly predict the sign of the anomaly at week-4 lead time for most of the regions with the exception of GEPS. The temperature anomaly at week-4 lead time is generally small compared to both ERA5 and to forecasts at week-1 lead time and it reaches only a maximum of $7^{\circ} \mathrm{C}$ over northern Canada (Fig. 7, bottom panel). It is interesting to note that although GEPS is the better model in reproducing the climatology as well as the subseasonal variability of SWE, the temperature forecast skill at a longer lead time is lower even over the regions where the snow on the ground appears to have an impact on temperature. This disparity could be explained by the weaker snow-atmosphere coupling in the GEPS model, which makes the air temperature forecast less sensitive to the anomalous high and low snow conditions. 

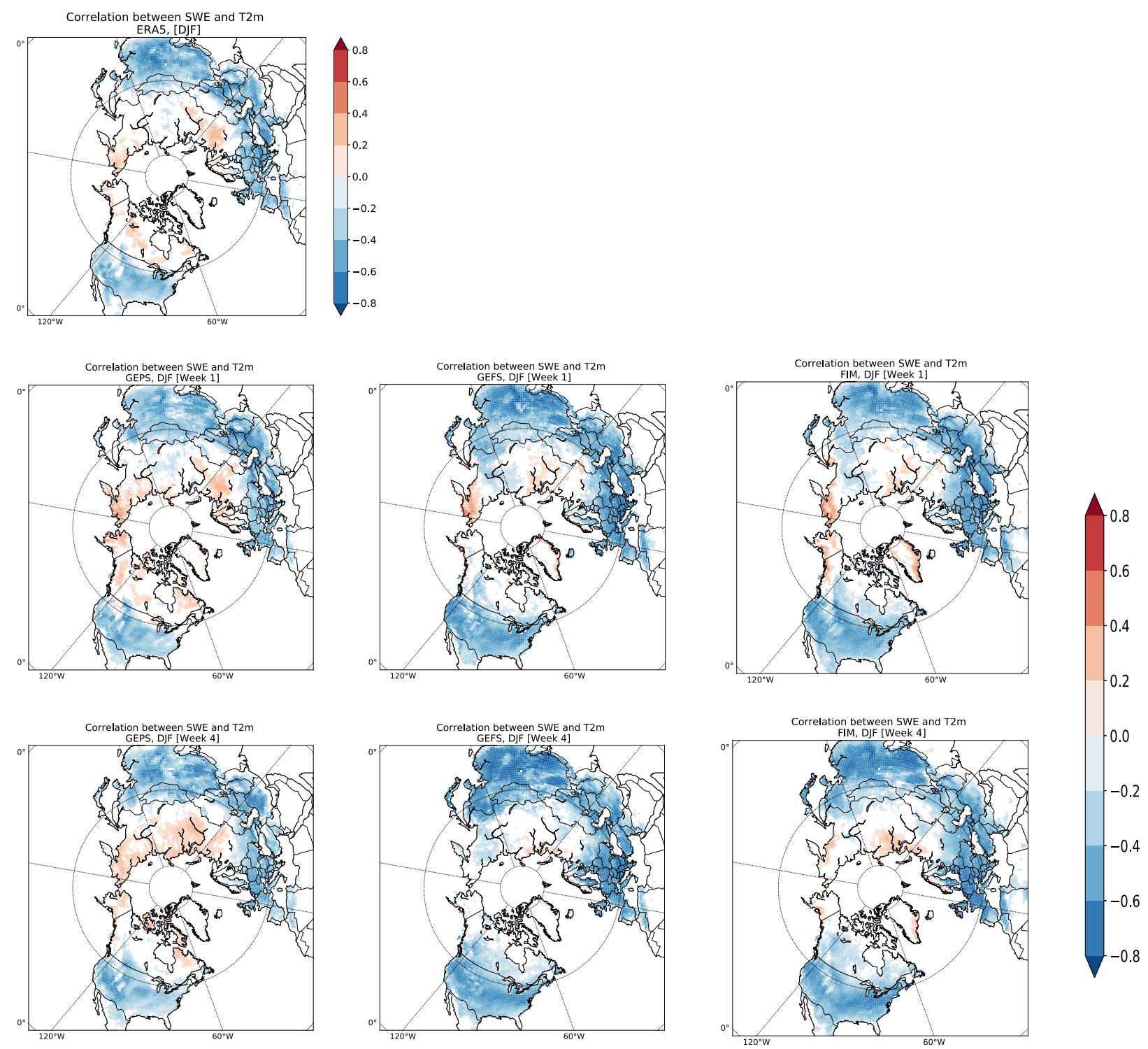

FIG. 6. Spatial pattern of correlation between SWE and T2m for (top) ERA5 and three forecast systems at (middle) week-1 and (bottom) week-4 lead times for (left) GEPS, (center) GEFS, and (right) FIM. Only significant correlations at the 0.05 level are displayed.

These results thus clearly show that, even if the skill of temperature forecast at a longer lead time (week 4) is weak, there are a number of regions in which models are able to reproduce the positive and negative temperature anomalies depending on the state of SWE conditions.

\section{Summary and conclusions}

This study examined the subseasonal forecast skill of SWE and its evolution with lead time, as well as the association of SWE with near-surface temperature using hindcast forecasts of three models (GEPS, GEFS, and
FIM) involved in the SubX project. All three forecast systems have systematic negative SWE biases over complex topography, although some of these biases are due to the inherent problem of the validation dataset (ERA5) itself. For GEFS and FIM, additional negative bias is found over eastern Canada and northern Asia. These negative SWE biases are found to decay as the forecast lead time increases. This suggests that the model SWE initial condition is lower but the models gradually produce enough SWE that is comparable to the validation ERA5 reanalysis to improve the bias. Comparing the forecast systems, GEPS better captured the forecast climatology and the subseasonal variability 

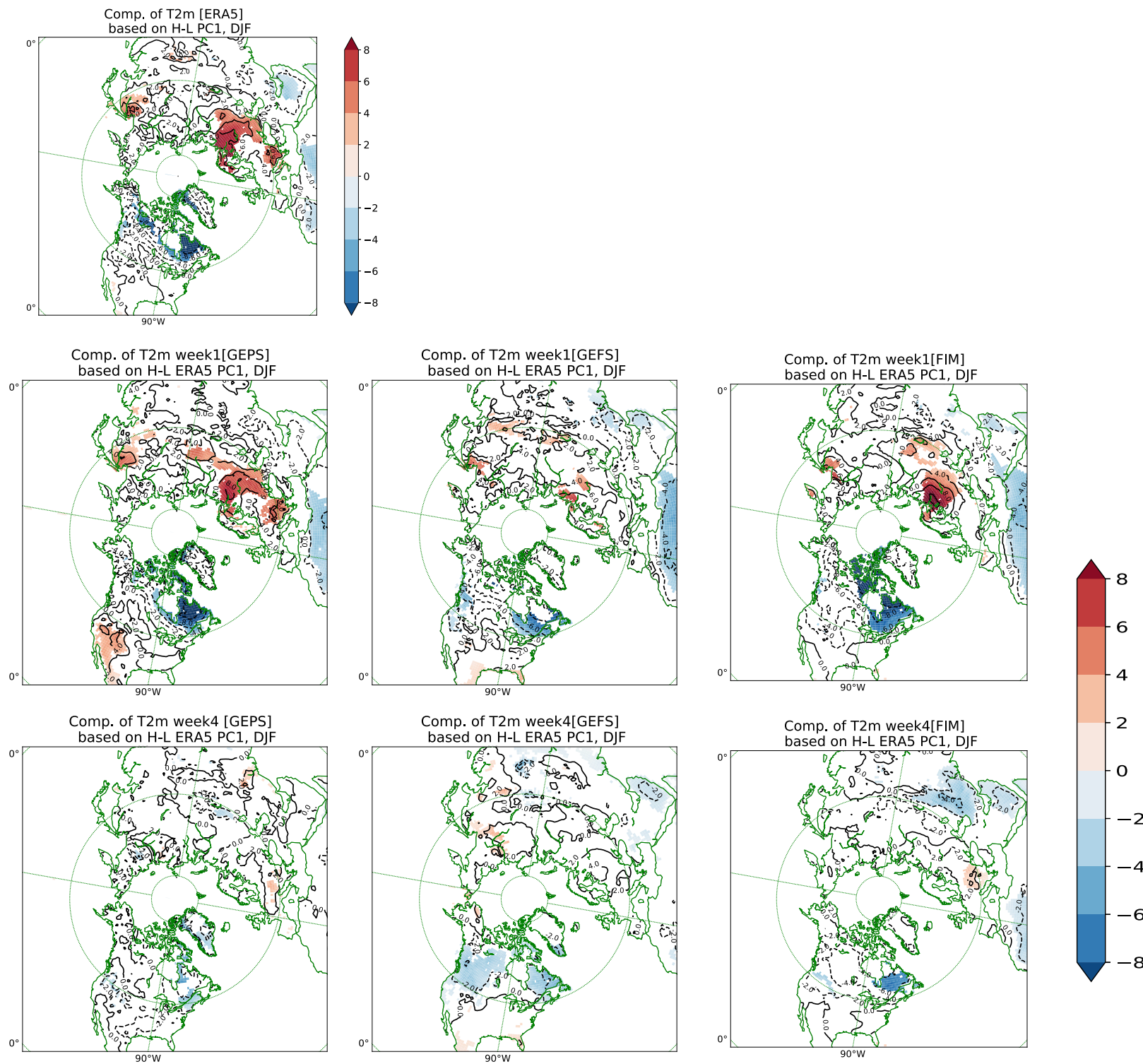

FIG. 7. Composites of $\mathrm{T} 2 \mathrm{~m}\left({ }^{\circ} \mathrm{C}\right)$ based on extreme high minus low $\mathrm{PC} 1$ values of SWE from (top) ERA5 and three forecast systems at (middle) week-1 and (bottom) week-4 lead times for (left) GEPS, (center) GEFS, and (right) FIM models. Extreme SWE weeks are chosen on the basis of the criterion that the magnitude of the ERA5 PC1 time series exceeds two standard deviations of the corresponding time series. Solid contour lines represent zero or positive anomalies, and dashed lines indicate negative anomalies. Shading indicates regions where the difference is statistically significant at the 0.05 level based on a Student's $t$ test.

compared to GEFS and FIM systems at a lead time of 1-4 weeks. As the lead time progresses, the models' temporal correlation decreases. We next proceed to analyze the large-scale leading pattern of SWE variability at a subseasonal time scale in observations and assess the extent to which the forecast systems reproduced the spatial and temporal variability of the leading modes of subseasonal variability of SWE. Our result suggests that GEPS reproduces the spatial and temporal characteristics of the leading mode of variability better than the other two models.
This study also documents the local SWE-temperature relationship and compares this relationship between observation and the three forecast systems. Analysis show that the local SWE-temperature coupling is stronger over the midlatitude regions of North America and Eurasia, and weakens near the pole. This spatial pattern is captured well by all three models, although the FIM and GEFS models have slightly stronger negative correlations over the midlatitudes and expand the region of negative correlations farther north compared to observations. GEPS forecasts, on the other hand, show slightly 
weaker correlation values and reasonably capture the observed transition of the local snow-temperature relationship for the high- and midlatitude regions.

The air temperature forecast anomalies associated with the high and low SWE condition suggests that the models can at least correctly predict the sign of the temperature anomaly at week-4 lead time associated with these snow anomalies over most of the domain although the correlation skill using all forecasts indicate that the skill at week 4 is practically null over the midand high-latitude regions. This implies that models with strong snow-atmosphere coupling strength can produce better forecast skill during anomalous SWE conditions.

Acknowledgments. This study was supported by NOAA's Climate Program Office's Modeling, Analysis, Predictions, and Projections program (Grant NOAAOAR-CPO-2016-2004413). The authors would like to acknowledge the European Centre for Medium-Range Weather Forecasts for providing ERA5 and the SubX project together with the IRI data library for making accessible the subseasonal hindcast data.

\section{REFERENCES}

Alemu, E. T., R. N. Palmer, A. Polebitski, and B. Meaker, 2011: Decision support system for optimizing reservoir operations using ensemble streamflow predictions. J. Water Resour. Plann. Manage., 137, 72-82, https://doi.org/10.1061/(ASCE) WR.1943-5452.0000088.

Bélair, S., R. Brown, J. Mailhot, B. Bilodeau, and L.-P. Crevier, 2003: Operational implementation of the ISBA land surface scheme in the Canadian regional weather forecast model. Part II: Cold season results. J. Hydrometeor., 4, 371-386, https:// doi.org/10.1175/1525-7541(2003)4<371:OIOTIL>2.0.CO;2.

Bogner, K., K. Liechti, L. Bernhard, S. Monhart, and M. Zappa, 2018: Skill of hydrological extended range forecasts for water resources management in Switzerland. Water Resour. Manage., 32, 969-984, https://doi.org/10.1007/s11269-017-1849-5.

Calanca, P., D. Bolius, A. Weigel, and M. Liniger, 2011: Application of long-range weather forecasts to agricultural decision problems in Europe. J. Agric. Sci., 149, 15-22, https://doi.org/10.1017/ S0021859610000729.

Davis, R. E., M. B. Lowit, P. C. Knappenberger, and D. R. Legates, 1999: A climatology of snowfall-temperature relationships in Canada. J. Geophys. Res., 104, 11 985-11994, https://doi.org/ 10.1029/1999JD900104.

Dee, D. P., and Coauthors, 2011: The ERA-Interim reanalysis: Configuration and performance of the data assimilation system. Quart. J. Roy. Meteor. Soc., 137, 553-597, https://doi.org/ 10.1002/qj.828.

Diro, G. T., and L. Sushama, 2018: Snow-precipitation coupling and related atmospheric feedbacks over North America. Atmos. Sci. Lett., 19, e831, https://doi.org/10.1002/asl.831.

,-- , and O. Huziy, 2018: Snow-atmosphere coupling and its impact on temperature variability and extremes over North America. Climate Dyn., 50, 2993-3007, https://doi.org/10.1007/ s00382-017-3788-5.
Dutra, E., C. Schär, P. Viterbo, and P. Miranda, 2011: Landatmosphere coupling associated with snow cover. Geophys. Res. Lett., 38, L15707, https://doi.org/10.1029/2011GL048435.

Ek, M., K. Mitchell, Y. Lin, E. Rogers, P. Grunmann, V. Koren, G. Gayno, and J. Tarpley, 2003: Implementation of Noah land surface model advances in the National Centers for Environmental Prediction operational mesoscale Eta model. J. Geophys. Res., 108, 8851, https://doi.org/10.1029/ 2002JD003296.

Foster, J., M. Owe, and A. Rango, 1983: Snow cover and temperature relationships in North America and Eurasia. J. Climate Appl. Meteor., 22, 460-469, https://doi.org/10.1175/1520-0450(1983) 022<0460:SCATRI $>2.0$.CO;2.

Helfrich, S. R., D. McNamara, B. H. Ramsay, T. Baldwin, and T. Kasheta, 2007: Enhancements to, and forthcoming developments in the interactive multisensor snow and Ice Mapping System (IMS). Hydrol. Processes, 21, 1576-1586, https://doi.org/ 10.1002/hyp.6720.

Hersbach, H., and D. Dee, 2016: Era5 reanalysis is in production. ECMWF Newsletter, No. 147, ECMWF, Reading, United Kingdom, 7, http://www.ecmwf.int/sites/default/files/elibrary/ 2016/16299-newsletter-no147-spring-2016.pdf.

Hirsch, A. L., J. Kala, A. J. Pitman, C. Carouge, J. P. Evans, V. Haverd, and D. Mocko, 2014: Impact of land surface initialization approach on subseasonal forecast skill: A regional analysis in the southern hemisphere. J. Hydrometeor., 15, 300319, https://doi.org/10.1175/JHM-D-13-05.1.

Hoeppe, P., 2016: Trends in weather related disasters-consequences for insurers and society. Wea. Climate Extremes, 11, 70-79, https://doi.org/10.1016/j.wace.2015.10.002.

Hudson, D., O. Alves, H. H. Hendon, and A. G. Marshall, 2011: Bridging the gap between weather and seasonal forecasting: Intraseasonal forecasting for Australia. Quart. J. Roy. Meteor. Soc., 137, 673-689, https://doi.org/10.1002/qj.769.

Jeong, J.-H., H. W. Linderholm, S.-H. Woo, C. Folland, B.-M. Kim, S.-J. Kim, and D. Chen, 2013: Impacts of snow initialization on subseasonal forecasts of surface air temperature for the cold season. J. Climate, 26, 1956-1972, https://doi.org/10.1175/ JCLI-D-12-00159.1.

Kopp, T., and R. Kiess, 1996: The air force global weather central cloud analysis model. Preprints, 15th Conf. on Weather Analysis and Forecasting, Norfolk, VA, Amer. Meteor. Soc., 220-222.

Koren, V., J. Schaake, K. Mitchell, Q.-Y. Duan, F. Chen, and J. Baker, 1999: A parameterization of snowpack and frozen ground intended for NCEP weather and climate models. J. Geophys. Res., 104, 19569-19585, https://doi.org/10.1029/ 1999JD900232.

Koster, R. D., and M. J. Suarez, 2003: Impact of land surface initialization on seasonal precipitation and temperature prediction. J. Hydrometeor., 4, 408-423, https://doi.org/10.1175/ 1525-7541(2003)4<408:IOLSIO > 2.0.CO;2.

_, and Coauthors, 2004: Regions of strong coupling between soil moisture and precipitation. Science, 305, 1138-1140, https://doi.org/10.1126/science.1100217.

_ zation to subseasonal forecast skill: First results from a multimodel experiment. Geophys. Res. Lett., 37, L02402, https:// doi.org/10.1029/2009GL041677.

Li, S., and A. W. Robertson, 2015: Evaluation of submonthly precipitation forecast skill from global ensemble prediction systems. Mon. Wea. Rev., 143, 2871-2889, https://doi.org/10.1175/ MWR-D-14-00277.1. 
Liang, P., H. Lin, and Y. Ding, 2018: Dominant modes of subseasonal variability of East Asian summertime surface air temperature and their predictions. J. Climate, 31, 2729-2743, https://doi.org/10.1175/JCLI-D-17-0368.1.

Lin, H., 2018: Predicting the dominant patterns of subseasonal variability of wintertime surface air temperature in extratropical Northern Hemisphere. Geophys. Res. Lett., 45, 43814389, https://doi.org/10.1029/2018GL077509.

_- , and G. Brunet, 2011: Impact of the North Atlantic oscillation on the forecast skill of the Madden-Julian Oscillation. Geophys. Res. Lett., 38, L02802, https://doi.org/10.1029/ 2010 GL046131.

—, N. Gagnon, S. Beauregard, R. Muncaster, M. Markovic, B. Denis, and M. Charron, 2016: GEPS-based monthly prediction at the Canadian Meteorological Centre. Mon. Wea. Rev., 144, 4867-4883, https://doi.org/10.1175/MWR-D-16-0138.1.

Lin, P., J. Wei, Z.-L. Yang, Y. Zhang, and K. Zhang, 2016: Snow data assimilation-constrained land initialization improves seasonal temperature prediction. Geophys. Res. Lett., 43, 11 423-11 432, https://doi.org/10.1002/2016GL070966.

Liu, X., S. Yang, Q. Li, A. Kumar, S. Weaver, and S. Liu, 2014: Subseasonal forecast skills and biases of global summer monsoons in the NCEP climate forecast system version 2. Climate Dyn., 42, 1487-1508, https://doi.org/10.1007/s00382-013-1831-8.

Lowe, R., M. García-Díez, J. Ballester, J. Creswick, J.-M. Robine, F. R. Herrmann, and X. Rodó, 2016: Evaluation of an earlywarning system for heat wave-related mortality in Europe: Implications for sub-seasonal to seasonal forecasting and climate services. Int. J. Environ. Res. Public Health, 13, 206, https://doi.org/10.3390/ijerph13020206.

Lynch, K. J., D. J. Brayshaw, and A. Charlton-Perez, 2014: Verification of European subseasonal wind speed forecasts. Mon. Wea. Rev., 142, 2978-2990, https://doi.org/10.1175/MWR-D-13-00341.1.

Noilhan, J., and S. Planton, 1989: A simple parameterization of land surface processes for meteorological models. Mon. Wea. Rev., 117, 536-549, https://doi.org/10.1175/1520-0493(1989) $117<0536$ :ASPOLS $>2.0$. CO;2.

Orsolini, Y., R. Senan, G. Balsamo, F. Doblas-Reyes, F. Vitart, A. Weisheimer, A. Carrasco, and R. Benestad, 2013: Impact of snow initialization on sub-seasonal forecasts. Climate Dyn., 41, 1969-1982, https://doi.org/10.1007/s00382-013-1782-0.

_- and Coauthors, 2019: Evaluation of snow depth and snowcover over the Tibetan plateau in global reanalyses using insitu and satellite remote sensing observations. Cryosphere, 13, 2221-2239, https://doi.org/10.5194/tc-13-2221-2019.

Paolino, D. A., J. L. Kinter III, B. P. Kirtman, D. Min, and D. M. Straus, 2012: The impact of land surface and atmospheric initialization on seasonal forecasts with CCSM. J. Climate, 25, 1007-1021, https://doi.org/10.1175/2011JCLI3934.1.

Pegion, K., and Coauthors, 2019: The Subseasonal Experiment (SubX): A multimodel subseasonal prediction experiment. Bull. Amer. Meteor. Soc., 100, 2043-2060, https://doi.org/10.1175/ BAMS-D-18-0270.1.

Prodhomme, C., F. Doblas-Reyes, O. Bellprat, and E. Dutra, 2016: Impact of land-surface initialization on sub-seasonal to seasonal forecasts over Europe. Climate Dyn., 47, 919-935, https:// doi.org/10.1007/s00382-015-2879-4.

Robertson, A. W., A. Kumar, M. Peña, and F. Vitart, 2015: Improving and promoting subseasonal to seasonal prediction. Bull. Amer. Meteor. Soc., 96, ES49-ES53, https://doi.org/ 10.1175/BAMS-D-14-00139.1.

Shah, R., A. K. Sahai, and V. Mishra, 2017: Short to sub-seasonal hydrologic forecast to manage water and agricultural resources in India. Hydrol. Earth Syst. Sci., 21, 707-720, https://doi.org/ 10.5194/hess-21-707-2017.

Sun, S., R. Bleck, S. G. Benjamin, B. W. Green, and G. A. Grell, 2018a: Subseasonal forecasting with an icosahedral, vertically quasi-Lagrangian coupled model. Part I: Model overview and evaluation of systematic errors. Mon. Wea. Rev., 146, 16011617, https://doi.org/10.1175/MWR-D-18-0006.1.

— B. W. Green, R. Bleck, and S. G. Benjamin, 2018b: Subseasonal forecasting with an icosahedral, vertically quasiLagrangian coupled model. Part II: Probabilistic and deterministic forecast skill. Mon. Wea. Rev., 146, 1619-1639, https:// doi.org/10.1175/MWR-D-18-0007.1.

Thomas, J. A., A. A. Berg, and W. J. Merryfield, 2016: Influence of snow and soil moisture initialization on sub-seasonal predictability and forecast skill in boreal spring. Climate Dyn., 47, 49-65, https://doi.org/10.1007/s00382-015-2821-9.

Tompkins, A. M., R. Lowe, H. Nissan, N. Martiny, P. Roucou, M. C. Thomson, and T. Nakazawa, 2019: Predicting climate impacts on health at sub-seasonal to seasonal timescales. SubSeasonal to Seasonal Prediction: The Gap between Weather and Climate Forecasting, A. W. Robertson and F. Vitart, Eds., Elsevier, 455-477.

Vigaud, N., A. W. Robertson, and M. K. Tippett, 2017: Multimodel ensembling of subseasonal precipitation forecasts over North America. Mon. Wea. Rev., 145, 3913-3928, https://doi.org/ 10.1175/MWR-D-17-0092.1.

Vitart, F., 2014: Evolution of ECMWF sub-seasonal forecast skill scores. Quart. J. Roy. Meteor. Soc., 140, 1889-1899, https:// doi.org/10.1002/qj.2256.

— A. W. Robertson, and D. L. Anderson, 2012: Subseasonal to seasonal prediction project: Bridging the gap between weather and climate. WMO Bull., 61 (2), https://public.wmo.int/en/ resources/bulletin/subseasonal-seasonal-prediction-projectbridging-gap-between-weather-and-climate.

_ - and Coauthors, 2017: The Subseasonal to Seasonal (S2S) prediction project database. Bull. Amer. Meteor. Soc., 98, 163173, https://doi.org/10.1175/BAMS-D-16-0017.1.

Wanders, N., and E. F. Wood, 2016: Improved sub-seasonal meteorological forecast skill using weighted multi-model ensemble simulations. Environ. Res. Lett., 11, 094007, https:// doi.org/10.1088/1748-9326/11/9/094007.

White, C. J., S. Franks, and D. McEvoy, 2015: Using subseasonalto-seasonal (S2S) extreme rainfall forecasts for extendedrange flood prediction in Australia. Proc. Int. Assoc. Hydrol. Sci., 370, 229-234, https://doi.org/10.5194/piahs-370-229-2015. , and Coauthors, 2017: Potential applications of subseasonalto-seasonal (S2S) predictions. Meteor. Appl., 24, 315-325, https://doi.org/10.1002/met.1654.

Xiang, B., S.-J. Lin, M. Zhao, N. C. Johnson, X. Yang, and X. Jiang, 2019: Subseasonal week 3-5 surface air temperature prediction during boreal wintertime in a GFDL model. Geophys. Res. Lett., 46, 416-425, https://doi.org/10.1029/2018GL081314.

Xu, L., and P. Dirmeyer, 2011: Snow-atmosphere coupling strength in a global atmospheric model. Geophys. Res. Lett., 38, L13401, https://doi.org/10.1029/2011GL048049.

Zhou, X., Y. Zhu, D. Hou, Y. Luo, J. Peng, and R. Wobus, 2017: Performance of the new NCEP global ensemble forecast system in a parallel experiment. Wea. Forecasting, 32, 1989-2004, https://doi.org/10.1175/WAF-D-17-0023.1.

Zhu, Y., and Coauthors, 2018: Toward the improvement of subseasonal prediction in the National Centers for Environmental Prediction Global Ensemble Forecast System. J. Geophys. Res. Atmos., 123, 6732-6745, https://doi.org/10.1029/2018JD028506. 